
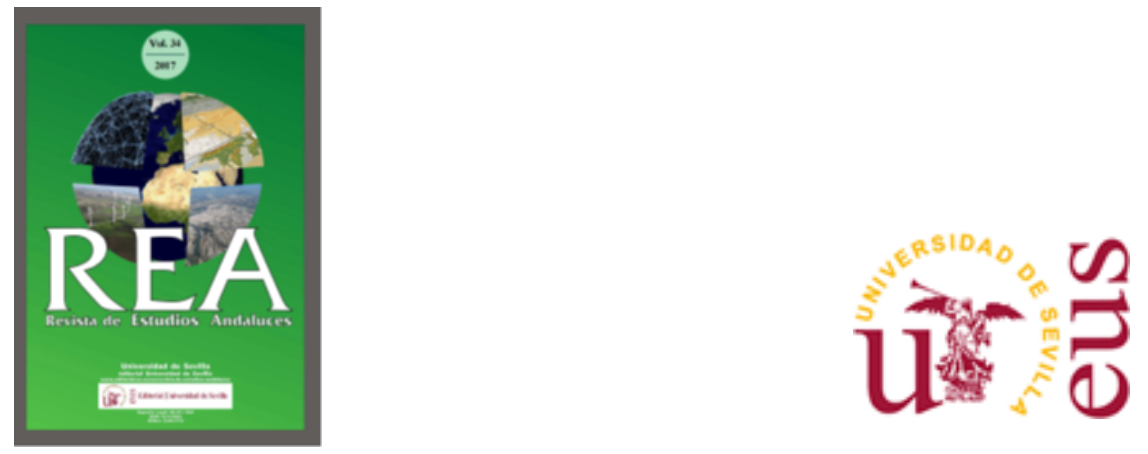

Revista de Estudios Andaluces (REA)

e-ISSN: $2340-2776$.

REA Vol. 34 (2017). http://dx.doi.org/10.12795/rea.2017.i34

\title{
Un Análisis Crítico de los Concursos Públicos de Contratación del Profesorado Universitario: Las Plazas de Profesorado Ayudante Doctor/a en Universidades Públicas Andaluzas
}

\section{A Critical Analysis on the Processes of Selection for Vacancies of Assistant Professor in Public Andalusian Universities}

\author{
Fernando García-Quero \\ Universidad de Granada \\ fgquero@ugr.es
}

Formato de cita / Citation: García-Quero, Fernando (2017). Un Análisis Crítico de los Concursos Públicos de Contratación del Profesorado Universitario: Las Plazas de Profesorado Ayudante Doctor/a en Universidades Públicas Andaluzas. Revista de Estudios Andaluces, vol. 34 (1), 529-543. http://dx.doi.org/10.12795/rea.2017.i34.18

Enlace artículo / to link to this article: http://dx.doi.org/10.12795/rea.2017.i34.18 


\title{
Un Análisis Crítico de los Concursos Públicos de Contratación del Profesorado Universitario: Las Plazas de Profesorado Ayudante Doctor/a en Universidades Públicas Andaluzas
}

\section{A Critical Analysis on the Processes of Selection for Vacancies of Assistant Professor in Public Andalusian Universities}

\author{
Fernando García-Quero \\ Universidad de Granada \\ fgquero@ugr.es
}

Recibido: 31 de enero, 2017

Revisado: 04 de abril, 2017

Aceptado: 05 de abril, 2017

\begin{abstract}
Resumen
La publicación del Real Decreto-ley 14/2012 de medidas urgentes de racionalización del gasto público paralizó la convocatoria de plazas de profesorado universitario. En muchas ocasiones la urgencia que lleva a reivindicar la necesidad de que se reactiven cuanto antes las promociones e incorporaciones de nuevo profesorado, hace olvidar que no basta únicamente con convocar concursos sino que éstos deben de regirse con criterios de transparencia, claridad, coherencia, justicia y objetividad. Si la aplicación de estos criterios es crucial en todos los casos, más lo es si cabe en los concursos de acceso para la adjudicación de plazas de Profesorado Ayudante Doctor/a debido puesto que suponen la puerta de entrada principal para la estabilidad contractual del profesorado en las Universidades Públicas. En esta aportación se analizan los concursos públicos para cubrir plazas de Profesorado Ayudante Doctor/a en las Universidades Públicas Andaluzas durante el periodo comprendido entre noviembre de 2014 y diciembre de 2015. El objetivo es mostrar cómo su marco regulatorio permite una enorme heterogeneidad y subjetividad en los procesos de contratación.
\end{abstract}

Palabras clave: Profesorado, calidad, contratación, concursos de acceso, Universidades Públicas de Andalucía.

Revista de Estudios Andaluces, vol. 34, núm. 1 (2017) pp. 529-543. e-ISSN: 2340-2776 http://dx.doi.org/10.12795/rea.2017.i34.18

(c) $($ ) $\odot \ominus$

cc) Esta obra se distribuye con la licencia Creative Commons Reconocimiento-NoComercialSinObraDerivada 4.0 Internacional 


\begin{abstract}
The publication of the royal decree, law 14/2012 of urgent measures of rationalisation of public spending, paralysed the opening of vacancies for university professors. The urgency to open new promotions and incorporate new professors means it is often easy to forget that it is not enough to just open new processes of selection but that selection for vacancies should take place in a transparent, clear, coherent, just and objective manner. If applying this criteria is crucial in every case, it is even more so with respect to vacancies for Assistant Professor, given that this is the key entry point for gaining a fixed professorship in public universities. In this article we analyse the processes of selection for vacancies of Assistant Professor in public Andalusian universities during the period between November 2014 and December 2015. Our objective is to show how the legal framework allows for a huge amount of heterogeneity and subjectivity in the hiring process.
\end{abstract}

Keywords: Professorate, quality, hiring, selection processes, Public Universities in Andalusia. 


\section{INTRODUCCIÓN}

Desde finales del año 2012 hasta el último trimestre de 2014 se ha producido un periodo de total sequía en lo que se refiere a la convocatoria de concursos públicos de acceso a las Universidades Públicas Españolas. El Real Decreto-ley 14/2012 de medidas urgentes de racionalización del gasto público en el ámbito educativo paralizó repentinamente la convocatoria de plazas de profesorado universitario. En cuestión de tres años, las Universidades Públicas Españolas han sufrido una degradación en las condiciones laborales de su profesorado. Miles de profesores y profesoras acreditados para los cuerpos docentes de Titulares y Catedráticos de Universidad están a la espera de que se convoquen los concursos que les permitan la posibilidad de promocionar de categoría. ${ }^{1} \mathrm{Al}$ mismo tiempo que se ha paralizado la promoción del profesorado, se han ido creando bolsas cada vez mayores de investigadores acreditados con las figuras de Ayudante Doctor, Contratado Doctor e incluso Titulares de Universidad que están aguantando la precariedad mediante contratos de investigación con cargo a proyectos, sustituciones de interinidad (a tiempo parcial o completo) o cobrando el paro mientras continúan investigando y publicando artículos, impartiendo másteres oficiales, dirigiendo trabajos fin de grado o de máster universitario e incluso coordinando proyectos de investigación.

Muchas veces la urgencia que lleva a reivindicar la necesidad de que se reactiven cuanto antes las promociones e incorporaciones de nuevo profesorado, hace olvidar que no basta únicamente con convocar concursos sino que éstos deben de realizarse con criterios de máxima transparencia, claridad, coherencia, justicia y objetividad. Si la aplicación de estos criterios es crucial en todos los casos, más lo es si cabe en los concursos de acceso para la adjudicación de plazas de Profesorado Ayudante Doctor/a puesto que suponen la puerta de entrada principal para que una persona haga carrera académica una vez que obtiene el doctorado. ${ }^{2}$ Sin embargo estos criterios no solo se incumplen sistemáticamente sino que las convocatorias para cubrir plazas de Profesorado Ayudante Doctor/a son de las menos transparentes y en las que las personas que se presentan se encuentran en una de las situaciones de mayor indefensión al ser uno de los eslabones más vulnerables de la cadena universitaria. ${ }^{3}$

\footnotetext{
1 Las referencias a personas, colectivos o cargos académicos figuran en esta nota en género masculino como género gramatical no marcado. Cuando proceda, será válida la cita de los preceptos correspondientes en género femenino. Respecto a los documentos consultados en este trabajo, exceptuando el caso de la Universidad de Jaén que matiza profesor/a, doctor/a, el resto de documentos consultados para la realización de este trabajo (BOJAS y baremos internos) utilizan género masculino como género gramatical no marcado.

2 Las promociones internas dentro de la Universidad, salvo alguna excepción como el caso de los contratos de investigación Ramón y Cajal, comienzan a partir de la figura de Ayudante Doctor/a.

3 También se han de mencionar la plazasconvocadas mediante concursos extraordinarios de Profesorado Sustituto/a Interino/a. Los baremos de estas plazas se asemejan a los de Ayudante Doctor/a. En estas convocatorias, cuyo uso está muy extendido en la Comunidad Autónoma de Andalucía, la precariedad del
}

Revista de Estudios Andaluces, vol. 34, núm. 1 (2017) pp. 529-543. e-ISSN: 2340-2776

http://dx.doi.org/10.12795/rea.2017.i34.18

\section{c) (i) (3)}

SinObraDerivada 4.0 Internacional 
Para demostrarlo a lo largo de este trabajo analizaré los concursos públicos para cubrir plazas de Profesorado Ayudante Doctor/a en las Universidades Públicas Andaluzas durante el periodo comprendido entre noviembre de 2014 y diciembre de 2015. Los documentos básicos de consulta han sido las resoluciones para la convocatoria de estas plazas publicadas en el Boletín Oficial de la Junta de Andalucía. También he utilizado documentos internos de algunas Universidades en los que se exponen especificidades de las baremaciones utilizadas en los concursos. Con la intención de mejorar la síntesis he elaborado dos tablas en las que se exponen las principales características de los concursos (Tabla 1) y ejemplos que muestran las diferencias entre las Universidades a la hora de evaluar los mismos méritos (Tabla 2 ). ${ }^{4}$

En lo que resta de trabajo se diferencian tres partes. En la primera se hace referencia a la falta de homogeneidad en los procesos de evaluación. Posteriormente se exponen doce propuestas para mejorar la transparencia en los concursos y objetivar las evaluaciones de méritos. Para terminar, se realiza una reflexión sobre la Universidad Pública y la necesidad urgente de acometer cambios en los concursos de acceso para permitir su mejora.

\section{HETEROGENEIDAD EN LOS PROCESOS DE EVALUACIÓN}

"De conformidad con lo establecido en el artículo 48.2 de la Ley Orgánica 6/2001, de 21 de diciembre, de Universidades (BOE núm. 307, de 24 de diciembre), modificada por la Ley Orgánica 4/2007, de 12 de abril (BOE núm. 89, de 13 abril), y en uso de las competencias que le atribuye el artículo 20 de la citada Ley, en relación con el artículo 2.2.e) de la misma norma; el artículo 40 del Texto Refundido de la Ley Andaluza de Universidades, aprobado por Decreto Legislativo 1/2013, de 8 de enero (BOJA núm. 8, de 11 de enero de 2013)."

Las dos frases con las que comienza el párrafo anterior son las primeras escritas en cualquier BOJA donde se publique una plaza para la contratación de Profesorado Ayudante Doctor/a en las distintas Universidades Públicas Andaluzas. No es el objetivo de este artículo estudiar la legislación universitaria sobre contrataciones, pero sí mostrar cómo establece un marco que deja margen de acción por parte de Universidades, en un primer lugar, de departamentos, en segundo, y de comisiones de evaluación, en tercero.

profesorado es enorme. Como ejemplo el nivel salarial que va desde $381 €$ (media jornada), $576 €$ (tres cuartos de jornada) hasta $1150 €$ netos (jornada completa, 24 créditos de docencia). En estas plazas no se reconoce complemento de doctorado aunque sí trienios docentes (12.93€ media jornada, $43 €$ jornada completa).

4 En la Tabla 2 he intentado seleccionar al menos un mérito de cada uno de los bloques que se bareman en las plazas. En algunos casos ha sido imposible puesto que algunas Universidades no coinciden entre ellas ni en el nombre de los bloques o evalúan méritos en bloques diferentes según sus apreciaciones (ver nota 1 Tabla 2). Las especificidades de algunas plazas me han obligado a acompañar ambas tablas de notas al pie. Recomiendo su lectura minuciosa porque se aclaran cuestiones que a mi juicio son fundamentales para respaldar mis argumentaciones. Para facilitar la lectura, las tablas aparecen al final del trabajo.

Revista de Estudios Andaluces, vol. 34, núm. 1 (2017) pp. 529-543. e-ISSN: 2340-2776 http://dx.doi.org/10.12795/rea.2017.i34.18

(c) (i) $(\Theta$

cc) Esta obra se distribuye con la licencia Creative Commons Reconocimiento-NoComercialSinObraDerivada 4.0 Internacional 
El paraguas tremendamente generalista de la legislación nacional y autonómica permite que cada Universidad tenga formularios de solicitud diferentes, incluya según sus propios criterios la necesidad o no de presentar compulsados algunos documentos o bareme los méritos (preferentes o normales) como estime conveniente (ver Tabla 1). ${ }^{5}$ La legislación vigente facilita que plazas salgan en algunas Universidades con perfil investigador y/o docente específico, que los criterios de valoración sean muy dispares y que se utilice el lenguaje como herramienta para dejar margen de maniobra a las comisiones para valorar los méritos (ver Tabla 2).

Mientras que unas Universidades permiten presentar toda la documentación digitalizada junto con una declaración responsable firmada en la que se verifica la veracidad de los méritos expuestos (Almería, Sevilla), otras solicitan la presentación de todas las fotocopias (Granada, Huelva, Málaga, Pablo de Olavide), de las fotocopias y compulsas (Córdoba, ver nota 3 Tabla 1), de las fotocopias y un ejemplar de las publicaciones (Jaén) ${ }^{6}$, o de las fotocopias y una autobaremación del candidato (Cádiz, ver nota 2 Tabla1). Es anecdótico el caso de la Universidad de Jaén por ser la única que requiere la presentación de una memoria docente junto con un proyecto curricular completo asociado al perfil de la plaza (ver nota 3 al pie de la Tabla 1).

¿Cómo es posible que departamentos equivalentes en Universidades distintas puedan no coincidir a la hora de puntuar los mismos méritos y ponderar su afinidad con el área? (ver Tabla 2). ¿Cómo es posible que haya plazas en las que los candidatos se presentan sin saber los criterios específicos con los que serán evaluados? (Universidad de Granada y Pablo de Olavide, ver notas 3 y 5 Tabla 2). ¿Por qué en algunas Universidades las plazas pueden salir con un perfil (formativo, docente, investigador) muy específico y en otras no? (Universidad de Almería, Cádiz, Córdoba, Jaén, Pablo de Olavide y Sevilla, ver columna 3 Tabla 1). Por coherencia, justicia y transparencia deben mejorar los procesos públicos de contratación.

\section{PROPUESTAS DE MEJORA Y EJEMPLOS DE ALEATORIEDAD EN LAS EVALUACIONES}

Es tan amplio el margen de mejora y los niveles en los que poder actuar que con escasas modificaciones sin coste monetario se daría un salto cualitativo en la calidad de los procesos selectivos. A continuación, se enumeran algunas posibilidades:

\footnotetext{
5 Los concursos de acceso se diferencian hasta en los precios públicos a pagar para solicitar la evaluación en una plaza. Mientras que concursar a una plaza en la Universidad de Cádiz es gratis en la de Córdoba cuesta 74,93€. En el resto de Universidades Andaluzas la cantidad oscila desde los $20 €$ de la Universidad de Sevilla a los $30 €$ de Granada y Jaén.

6 Matiza que "la no presentación de la documentación señalada o su presentación fuera del plazo establecido, no supondrá la exclusión del concurso, pero podrá conllevar su no consideración por parte de la Comisión".
}

Revista de Estudios Andaluces, vol. 34, núm. 1 (2017) pp. 529-543. e-ISSN: 2340-2776 http://dx.doi.org/10.12795/rea.2017.i34.18 
1. Homogenizar formatos de Currículo Vitae (CV en adelante) y formularios de solicitud. Todos los investigadores e investigadoras poseen CV en formato normalizado y en formato ANECA, cuestión óptima para utilizar uno de estos formatos en los concursos.

2. Homogeneizar los criterios de evaluación para acreditaciones y plazas.

3. Especificar claramente en cada apartado qué méritos se incluyen y cuáles no. Existe un déficit informativo $y$, en muchas ocasiones, los candidatos no saben con certeza dónde incluir algunos méritos para su adecuada evaluación. También debe de puntualizarse la imposibilidad de duplicar méritos o, en caso de que haya méritos computables en dos apartados, exponer estas posibilidades con claridad.

4. En el mismo momento que se publique la convocatoria de plazas debe de aclararse con exactitud el valor de cada uno de los méritos, objetivándolo en todo lo posible. También es necesario especificar en la misma convocatoria las afinidades del área, justificando y objetivando cómo y por qué se aplican coeficientes de corrección a los méritos. No es suficiente con decir "Se aplica un coeficiente de 0.5 por menor afinidad del candidato con el área". ¿En base a qué tiene un mérito menor afinidad? En el caso de algunas Universidades existe la posibilidad de aplicar dobles e incluso triples penalizaciones para algunos méritos puesto que se pondera negativamente su puntuación por "no afinidad", posteriormente se vuelve a ponderar negativamente la puntuación del bloque donde se encuentra el mérito y por último hay un bloque concreto para volver a ponderar las puntuaciones totales del candidato en cuestión o puntuar positivamente a otros y no a éste. Los BOJAS de las convocatorias consultadas, con la excepción de la Universidad de Huelva que establece una tabla de afinidades más completa aunque también insuficiente, exponen párrafos del tipo:

"Todas las aportaciones serán valoradas, sean propias o no del área de conocimiento de la plaza, salvo en aquéllos apartados en los que explícitamente se exige relevancia o relación con la plaza. En algunos tipos de mérito se aplicará una modulación de acuerdo con la afinidad al área de la plaza, de forma que las contribuciones consideradas propias del área computarán el 100\% del valor asignado en el baremo, las consideradas de áreas afines computarán el $50 \%$ y las de áreas no afines el 20\%. En cualquier caso, los méritos del apartado III se modularán de forma que las contribuciones propias del área realizadas dentro de las líneas de investigación desarrolladas por Grupos de Investigación de la Universidad de Jaén computarán el 100\%, las consideradas propias del área pero desarrolladas fuera del ámbito investigador mencionado computarán el $50 \%$ del valor asignado en el baremo, las consideradas de áreas afines computarán el $30 \%$ y las de áreas no afines el 15\%" (Jaén).

"La valoración de los méritos alegados por los candidatos en cada una de las dimensiones contempladas en el baremo se realizará de acuerdo con la coherencia y correspondencia de dichos méritos con el área de conocimiento de la plaza a la que concursa" (Málaga).

Revista de Estudios Andaluces, vol. 34, núm. 1 (2017) pp. 529-543. e-ISSN: 2340-2776 http://dx.doi.org/10.12795/rea.2017.i34.18 
"Se entiende por afinidad y áreas de conocimiento afines, aquellas vinculadas y capacitadas por el plan de estudios correspondiente para la impartición de una determinada asignatura. Lo anterior no será de aplicación en aspectos de formación académica, donde todas las contribuciones del mismo tipo computarán por igual, ni en aspectos de investigación, formación complementaria y experiencia profesional, donde sólo se considerarán las contribuciones que tengan relación con la plaza. En algunos tipos de mérito se aplicará una modulación de acuerdo con la afinidad al área de la plaza. De este modo, las contribuciones consideradas propias del área computarán el 100\% del valor asignado en el baremo, las consideradas de áreas afines computarán el 50\% y las de áreas no afines el 20\%" (Almería).

5. Especificar al detalle cuestiones que dejan mucho margen para la interpretación de las comisiones. Por ejemplo, la aclaración del significado de tiempo completo. No es lo mismo dar 6, 12, 18, 24 o 32 créditos al año de docencia; sin embargo, algunas Universidades le otorgan la misma puntuación puesto que no especifican lo que significa tiempo completo (Universidad de Cádiz, Granada, Huelva, Málaga y Sevilla, ver columna 4 Tabla 2 para más detalles). He cuidado la redacción de la Tabla 2 ya que el simple hecho de cambiar mínimamente el lenguaje utilizado en la baremación de un mérito permite aumentar sustancialmente el margen de subjetividad por parte de la comisión evaluadora. Como puede comprobarse en la Tabla 2, es común que los baremos utilicen la preposición "hasta" o intervalos de puntuación para los méritos. En ambos casos, si no se especifica con claridad en base a qué se diferenciarán las puntuaciones, se vuelve a dar una herramienta subjetiva para que las comisiones lo interpreten como estimen oportuno.

6. Entrega de la instancia $\mathrm{CV}$ en formato digital y exposición de la misma en una plataforma web en abierto para que el CV de los solicitantes pueda ser consultado, por quien lo desee, independientemente de que forme parte del concurso o no. Habría que adecuarlo a las leyes de protección de datos y evitar que se puedan mostrar informaciones confidenciales como, por ejemplo, el número de NIF. Esta medida reduciría las reclamaciones e impugnaciones, ahorrando costes. ${ }^{7}$

7. Imposibilidad de que miembros del tribunal tengan publicaciones en coautoría, sean familiares o hayan dirigido tesis doctorales a personas que se presentan al concurso.

\footnotetext{
7 Me parece importante señalar el elevado número de recursos de alzada, de reposición y/o contenciosos administrativos que se producen una vez se resuelven las plazas de Profesorado Ayudante Doctor/a. Algunos de ellos se producen incluso con anterioridad a la resolución puesto que se hacen contra los propios baremos de contratación. Este hecho no solo da muestras de posibles errores en los baremos, evaluaciones, etc., también tiene costes económicos y temporales para las Universidades y para las personas implicadas en los procesos. Sería muy interesante que se hicieran análisis exhaustivos sobre esta cuestión.
}

Revista de Estudios Andaluces, vol. 34, núm. 1 (2017) pp. 529-543. e-ISSN: 2340-2776 http://dx.doi.org/10.12795/rea.2017.i34.18

\section{cc) (i) (3)}

SinObraDerivada 4.0 Internacional 
Algunas becas competitivas pre-doctorales ya utilizan estos criterios a la hora de elegir a los pares que evalúan las solicitudes.

8. Crear comisiones mixtas de evaluación con miembros de diferentes departamentos e incluso de disciplinas o áreas distintas.

9. Establecer responsabilidades para los candidatos en caso de incurrir en falacias en los CV y para los miembros de las comisiones de evaluación si se demostrasen comportamientos fraudulentos.

10. Reconocer a las personas que realizan las evaluaciones el trabajo que ello supone. No está ni valorado ni visibilizado el esfuerzo y la responsabilidad que conlleva el proceso de evaluación.

11. Incorporar en los concursos de acceso para personal laboral algún tipo de prueba que conlleven una defensa pública y oral de un tema y/o CV del candidato. No es lógico que una persona pueda entrar a trabajar en un lugar como la Universidad y se desconozca su forma de expresarse, sus cualidades de comunicación, sus nociones docentes, etc.

12. Tener en consideración en los debates sobre mejora de política universitaria a personas que recientemente hayan sido candidatas en estos concursos.

\section{REFLEXIONES FINALES}

La mayoría de los departamentos y de las personas que forman parte de las comisiones de evaluación se preocupan por estas cuestiones y las incorporan en la medida de sus posibilidades. Sin embargo, tienen limitadas ciertas actuaciones puesto que no dependen directamente de ellas. Una Universidad que apuesta por la transparencia no debe permitir la opacidad en los concursos de acceso ni arbitrariedades en las decisiones de contratación. Por lo general, no existen malas intenciones a la hora de regular y evaluar las plazas, pero sí se observan reticencias en las Universidades para incluir mejoras de manera coordinada. Muchas de las medidas que podrían implementarse son a coste cero. En la mayor parte de las ocasiones sería suficiente con reflexionar cómo se están haciendo ciertos procedimientos para darse cuenta de que con mínimos cambios mejorarían sustancialmente los procesos de contratación.

A lo largo de esta aportación ha podido parecer que las únicas víctimas de este proceso son las personas que se presentan a los concursos y no es exactamente así. Creo que son otra pieza oprimida del sistema, quizás la más débil y en la que menos se repara. Sin embargo, también considero víctimas a los rectores que están trabajando para intentar defender el sistema público universitario, a los directores de departamento que intentan consolidar a personas muy valiosas que han dado muestras más que objetivas de sus capacidades, al profesorado que forma parte de las comisiones de evaluación

Revista de Estudios Andaluces, vol. 34, núm. 1 (2017) pp. 529-543. e-ISSN: 2340-2776 http://dx.doi.org/10.12795/rea.2017.i34.18 
tratando de objetivar lo que a veces no permite la legislación, a sindicalistas que tratan de defender derechos enfrentados o a las personas administrativas que entre otras labores procesan todos los documentos de los concursos. Ahora bien, las responsabilidades no son las mismas y si alguien, por su cargo, debe garantizar concursos de acceso a la Universidad transparentes y justos, tiene que hacerlo o abandonar su puesto.

Desafortunadamente, y estos son otros temas, el sistema actual lleva a las prisas, a la calidad mal entendida, a subir posicionamientos en rankings que no reflejan muchos aspectos relevantes, a ritmos profesionales y vitales acelerados. Quizás todo esto forme parte de una estrategia interesada en destruir y desacreditar lo público. Justo para lo contrario, pues soy defensor acérrimo de una Universidad Pública Universal, hay que acometer cambios cuanto antes. Los concursos de acceso a las Universidades Públicas son sin duda una oportunidad inmejorable para comenzar.

Revista de Estudios Andaluces, vol. 34, núm. 1 (2017) pp. 529-543. e-ISSN: 2340-2776 http://dx.doi.org/10.12795/rea.2017.i34.18

\section{(c) (i) (3)} SinObraDerivada 4.0 Internacional 
Tabla 1. Principales características de los concursos de Ayudante Doctor/a en Universidades Públicas Andaluzas

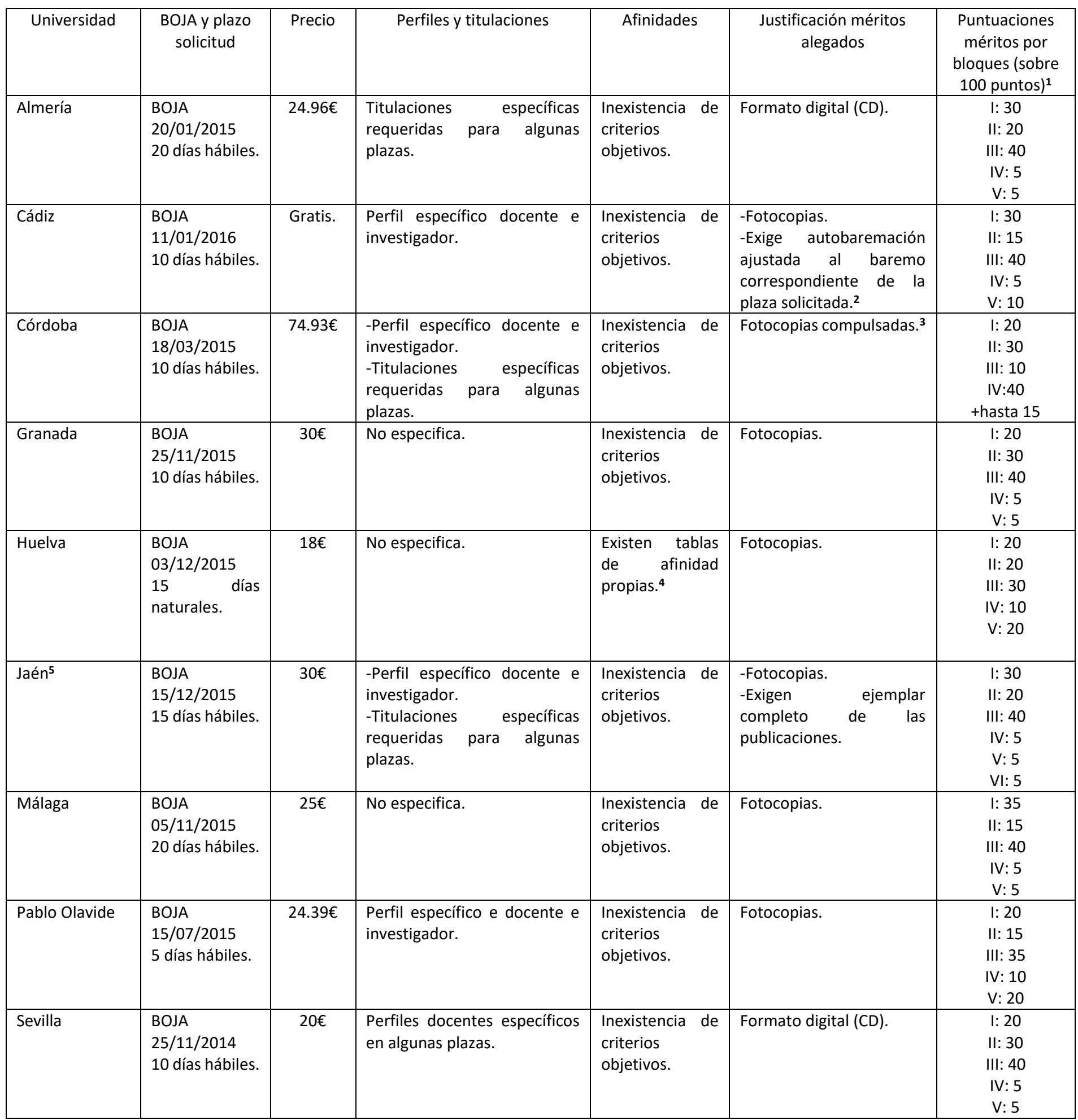

Fuente: Elaboración propia a partir de las convocatorias de los Boletines Oficiales autonómicos donde se han publicado las plazas de AD en las Universidades mencionadas.

Revista de Estudios Andaluces, vol. 34, núm. 1 (2017) pp. 529-543. e-ISSN: 2340-2776 http://dx.doi.org/10.12795/rea.2017.i34.18

(c) (i) (9) Esta obra se distribuye con la licencia Creative Commons Reconocimiento-NoComercialSinObraDerivada 4.0 Internacional 


\section{Notas Tabla 1}

1. Hay 5 bloques para evaluar los méritos: I. Formación académica. II. Actividad docente. III Actividad Investigadora. IV. Experiencia profesional. V. Representación, gobierno y gestión universitaria. Los méritos de cada bloque multiplicándolos por coeficientes de corrección según la afinidad de cada mérito. Los coeficientes van desde 0.2 hasta 1. En la Universidad Sevilla el apartado IV se denomina "Otros méritos" y el V "Valoración razonada del departamento". La Universidad de Jaén también incorpora un bloque VI que se corresponde con "Informe del departamento". La Universidad de Córdoba varía los bloques respecto al resto de Universidades consultadas: 1으 Formación académica y Gestión; 2ㅇ) Actividad docente y Experiencia profesional/clínica; 3ㅇ) Becas y Contratos; 4을 Actividad investigadora y de transferencia. La puntuación final del o de los candidato/s en la Universidad de Córdoba podrá verse incrementada a su vez con el porcentaje del $15 \%$ adjudicado por el Departamento para las figuras PDI-Laboral de Ayudante y Profesor Ayudante Doctor según criterio de Afinidad. En la Universidad de Cádiz la puntuación obtenida final podrá incrementarse por parte del departamento con el porcentaje de hasta el $10 \%$ de dicha puntuación. La Universidad Pablo de Olavide solo diferencias 4 bloques. Para facilitar la comparación, se diferencian 5 puesto al dividir su bloque II "Docencia e Investigación" en dos bloques (II Docencia, III Investigación), respetando los porcentajes de puntuación en cada uno de ellos. Su último bloque (V) se diferencia de todos los bloques expuestos hasta el momento y se denomina "Adecuación de los méritos del concursante a las necesidades docentes e investigadoras de la Universidad Pablo de Olavide". En la Universidad de Huelva el bloque 5 se denomina "Puntuación departamento".

2. La Universidad de Cádiz especifica lo siguiente: "El procedimiento de selección de los aspirantes será el de concurso público, consistente en una primera autobaremación por parte de los candidatos, seguida de una propuesta de baremación de los méritos de los mismos por parte del correspondiente Departamento, para una última baremación de carácter definitivo de la Comisión de Contratación de la Universidad".

3. En caso de no compulsar los méritos, el candidato/a puede firmar en cada una de las fotocopias exponiendo que el documento "es copia de su original".

4. Las afinidades suelen ser generales del tipo " $100 \%$ cuando, a juicio de la comisión, se desarrolle en el ámbito del Área de Metodología de las Ciencias del Comportamiento"; "50\% Cuando se desarrolle en el ámbito de las áreas de Psicobiología; Psicología Básica; Psicología Evolutiva y de la Educación; Psicología Social; y Personalidad, Evaluación y Tratamiento Psicológico, y, a juicio de la comisión, esté relacionado con el Área de Metodología de las Ciencias del Comportamiento”; "25\% Cuando se desarrolle en el ámbito de las áreas de Psicobiología; Psicología Básica; Psicología Evolutiva y de la Educación; Psicología Social; y Personalidad, Evaluación y Tratamiento Psicológico, y, a juicio de la comisión, no guarde relación con el Área de Metodología de las Ciencias del Comportamiento"; "0\% Cuando se desarrolle en otros ámbitos". 5. En la Universidad de Jaén es obligatorio presentar junto con la solicitud de la plaza una memoria docente con un proyecto curricular completo asociado al perfil de la plaza. "El Departamento valorará la memoria y podrá solicitar al candidato su presentación oral sometiéndole a las preguntas que realicen los miembros designados por el Departamento. Los criterios de valoración del Departamento deberán exponerse en el tablón de anuncios de la Universidad de Jaén y en el tablón de anuncios del Departamento. En caso de requerir la presentación oral de la memoria, ésta se hará en acto público. El Departamento deberá citar a los candidatos con una antelación mínima de diez días naturales. La intervención de los candidatos se hará en orden alfabético. La valoración del Departamento deberá estar justificada en función de los criterios publicados. En ningún caso el informe del Departamento podrá suponer más del $50 \%$ de la puntuación obtenida por el candidato como resultado de la suma de las puntuaciones obtenidas en el resto de apartados" (BOJA 15/12/2015, pág. 32).

Revista de Estudios Andaluces, vol. 34, núm. 1 (2017) pp. 529-543. e-ISSN: 2340-2776

http://dx.doi.org/10.12795/rea.2017.i34.18

(c)

SinObraDerivada 4.0 Internacional 
Tabla 2. Ejemplos de puntuaciones para méritos del CV alegados en diferentes bloques.

\begin{tabular}{|c|c|c|c|c|c|c|}
\hline & Bloque I & Bloque I & Bloque II & Bloque III & Bloque III & Bloque III \\
\hline Universidad & $\begin{array}{l}\text { Meses de } \\
\text { becario como } \\
\text { alumno } \\
\text { colaborador. }\end{array}$ & $\begin{array}{c}\text { Estancias pre- } \\
\text { doctorales en el } \\
\text { extranjero y en } \\
\text { territorio nacional. }\end{array}$ & $\begin{array}{l}\text { Por año de } \\
\text { docencia } \\
\text { universitaria en } \\
\text { grado a tiempo } \\
\text { completo. }\end{array}$ & $\begin{array}{l}\text { Por artículos } \\
\text { en revistas } \\
\text { indexadas de } \\
\text { reconocido } \\
\text { prestigio } \\
\text { internacional. }\end{array}$ & $\begin{array}{l}\text { Por comunicación } \\
\text { a congresos } \\
\text { internacionales. }\end{array}$ & $\begin{array}{l}\text { Por proyecto de } \\
\text { investigación } \\
\text { (internacional, } \\
\text { nacionales y } \\
\text { autonómicos). }\end{array}$ \\
\hline Almería & 0.05 por mes. & $\begin{array}{l}0.2 \text { por mes } \\
\text { (internacionales) } \\
0.1 \text { por mes } \\
\text { (nacionales). }\end{array}$ & $\begin{array}{l}3 \text { puntos } \\
\text { Un año completo } \\
\text { se corresponde } \\
\text { con } 24 \text { créditos. }\end{array}$ & $\begin{array}{l}3 \text { puntos } \\
\text { Revistas JCR. }{ }^{1} \\
\text { No especifica } \\
\text { nada de cuartil, } \\
\text { etc. }\end{array}$ & 0.4 puntos. & $\begin{array}{l}6 \text { puntos } \\
\text { (internacional) } \\
3 \text { puntos (nacional) } \\
\text { No especifica rol, } \\
\text { dedicación } \\
\text { tiempo. }\end{array}$ \\
\hline Cádiz & $\begin{array}{l}0.3 \text { por año o } \\
\text { hasta } 1 \text { punto } \\
\text { en el } \\
\text { apartado } \\
\text { "Otros } \\
\text { méritos". }\end{array}$ & $\begin{array}{l}2 \text { puntos por año } \\
\text { en centro de } \\
\text { excelencia (no } \\
\text { diferencia ámbito). } \\
1 \text { punto por año en } \\
\text { "otros centros". }\end{array}$ & $\begin{array}{ll}3 \quad \text { puntos } & \text { por } \\
\text { tiempo } & \\
\text { completo. } & \text { No } \\
\text { especifica } & \\
\text { número } & \text { de } \\
\text { créditos. } & \end{array}$ & $\begin{array}{l}\text { Hasta } 3 \text { puntos. } \\
\text { Según nivel de } \\
\text { impacto. No } \\
\text { especifica base } \\
\text { datos ni cuartil, } \\
\text { etc. }\end{array}$ & $\begin{array}{l}\text { De } 0.25 \text { a } 1 . \\
\text { Especifica tipo de } \\
\text { contribución } \\
\text { (póster, } \\
\text { comunicación) y } \\
\text { ámbito (nacional, } \\
\text { internacional). }\end{array}$ & $\begin{array}{l}1 \text { punto por } \\
\text { dirección y } 0.5 \text { por } \\
\text { participación. } \\
\text { Puntuación por } \\
\text { año. No especifica } \\
\text { ámbito. }\end{array}$ \\
\hline Córdoba $^{2}$ & $\begin{array}{l}1 \text { punto por } \\
\text { curso. }\end{array}$ & $\begin{array}{l}1 \text { punto por año } \\
\text { (nacionales) y } 2 \\
\text { puntos por año } \\
\text { (internacionales). }\end{array}$ & $\begin{array}{l}0,1 \\
\text { puntos/crédito y } \\
\text { curso. } \\
\text { Asignaturas } \\
\text { adscritas al área } \\
\text { de conocimiento } \\
\text { objeto del } \\
\text { concurso. }\end{array}$ & $\begin{array}{l}\text { Revistas JCR o } \\
\text { índice } \\
\text { aceptado por la } \\
\text { CNEAl. } \\
\text { Puntos } \\
\text { especificados } \\
\text { por decil y } \\
\text { posición del } \\
\text { autor. }\end{array}$ & $\begin{array}{l}\text { De } 0.025 \text { a } 0.5 \text {. } \\
\text { Especifica por tipo } \\
\text { de contribución } \\
\text { (póster, } \\
\text { comunicación) y } \\
\text { ámbito (nacional, } \\
\text { internacional). }\end{array}$ & $\begin{array}{lr}\begin{array}{l}\text { Entre } 1.5 \text { y } \\
\text { puntos }\end{array} \\
\text { proyecto. } \\
\text { Especifica ámbito } \\
\text { (autonómico, } \\
\text { nacional, } \\
\text { internacional) } \\
\text { participación. }\end{array}$ \\
\hline Granada ${ }^{3}$ & $\begin{array}{l}\text { No especifica. } \\
\text { Cada } \\
\text { comisión } \\
\text { tiene como } \\
\text { referencia el } \\
\text { BOJA } \\
8 / 8 / 2011 \\
\end{array}$ & $\begin{array}{l}\text { No especifica. } \\
\text { Cada comisión } \\
\text { tiene como } \\
\text { referencia el BOJA } \\
8 / 8 / 2011\end{array}$ & $\begin{array}{l}\text { Hasta } 4 \text { puntos } \\
\text { por año a tiempo } \\
\text { completo. } \\
\text { No especifica } \\
\text { significado de } \\
\text { "tiempo } \\
\text { completo". }\end{array}$ & $\begin{array}{l}\text { No especifica. } \\
\text { Cada comisión } \\
\text { tiene como } \\
\text { referencia el } \\
\text { BOJA 8/8/2011 }\end{array}$ & $\begin{array}{l}\text { No especifica. } \\
\text { Cada comisión } \\
\text { tiene como } \\
\text { referencia el BOJA } \\
8 / 8 / 2011\end{array}$ & $\begin{array}{l}\text { No especifica. } \\
\text { Cada comisión } \\
\text { tiene } \quad \text { como } \\
\text { referencia el } \text { BOJA } \\
8 / 8 / 2011\end{array}$ \\
\hline Huelva ${ }^{4}$ & 0.8 por año. & $\begin{array}{l}0.6 \text { por mes } \\
\text { (extranjero habla } \\
\text { no española) } \\
0.4 \quad \text { (extranjero } \\
\text { habla española) } \\
0.2 \text { (España). }\end{array}$ & \begin{tabular}{lr}
\multicolumn{2}{l}{ puntos por año } \\
a $r$ tiempo \\
completo. & Hasta \\
1 punto & por \\
parcial. & No \\
específica & \\
significado & \\
tiempo r & \\
completo. &
\end{tabular} & $\begin{array}{lr}\text { De } 0.3 \text { a } & 3 \\
\text { puntos. } & \\
\text { Diferencia } & 4 \\
\text { tipos } & (A, B, C, D) \\
\text { en función base } \\
\text { datos y } \\
\text { posición (JCR). }{ }^{4}\end{array}$ & $\begin{array}{l}\text { De } 0.2 \text { a } 1 . \\
\text { Especifica por tipo } \\
\text { de contribución } \\
\text { (ponencia } \\
\text { invitada, } \\
\text { comunicación o } \\
\text { trabajo extenso } \\
\text { con ISBN) y ámbito } \\
\text { (nacional, } \\
\text { internacional). }\end{array}$ & $\begin{array}{lr}\text { Máximo } 4 & \text { puntos } \\
\text { Diferencia } & \text { entre } \\
\text { competitivo } & \\
\text { internacional } & \text { (2 } \\
\text { puntos) } & \text { y } \\
\text { competitivo } & \\
\text { nacional } & \text { (1.5 } \\
\text { puntos). } & \text { No } \\
\text { especifica } & \text { rol, } \\
\text { dedicación } & \text { y } \\
\text { tiempo. } & \end{array}$ \\
\hline Jaén & No especifica. & 0.2 por mes. & $\begin{array}{l}\text { 0.125 por crédito } \\
\text { (el valor unitario } \\
\text { equivale a } 24 \\
\text { créditos). }\end{array}$ & $\begin{array}{lr}\text { Hasta } & 3.6 \\
\text { puntos. } & \\
\text { Revistas JCR. } \\
\text { Detalla } & \text { puntos } \\
\text { exactos } & \text { en } \\
\text { función } & \text { del } \\
\text { cuartil. } & \\
\end{array}$ & $\begin{array}{l}0.9 \quad \text { puntos } \\
\text { internacionales } \\
0.5 \text { nacionales. }\end{array}$ & $\begin{array}{l}2.5 \text { puntos } \\
\text { (internacional) } \\
1.5 \text { puntos } \\
\text { (nacional) } \\
1 \text { (autonómico) } \\
0.5 \text { (local) }\end{array}$ \\
\hline
\end{tabular}

Revista de Estudios Andaluces, vol. 34, núm. 1 (2017) pp. 529-543. e-ISSN: 2340-2776 http://dx.doi.org/10.12795/rea.2017.i34.18 (c) (i) (3) 


\begin{tabular}{|c|c|c|c|c|c|c|}
\hline & & & & & & $\begin{array}{lr}\text { No especifica } & \text { rol, } \\
\text { dedicación } & y \\
\text { tiempo. } & \\
\end{array}$ \\
\hline Málaga & $\begin{array}{l}0.042 \text { por } \\
\text { mes. }\end{array}$ & $\begin{array}{l}\text { Diferencia por } \\
\text { pregrado ( } 0.15 \text { por } \\
\text { mes) y posgrado } \\
\text { ( } 0.30 \text { por mes). }\end{array}$ & $\begin{array}{l}2 \text { puntos } \\
\text { No específica el } \\
\text { significado de } \\
\text { "tiempo } \\
\text { completo" ni el } \\
\text { número de } \\
\text { créditos. }\end{array}$ & $\begin{array}{l}\text { De } 2 \text { a } 4 \text { puntos } \\
\text { Revistas JCR. } \\
\text { No especifica } \\
\text { nada de cuartil, } \\
\text { etc. }\end{array}$ & $\begin{array}{l}\text { De } 0.5 \text { a } 1 \text { punto } \\
\text { Congresos } \\
\text { sometidos a un } \\
\text { procedimiento } \\
\text { selectivo. } \\
\text { Diferencia } \\
\text { comunicación } \\
\text { oral, póster, etc. }\end{array}$ & $\begin{array}{l}\text { De } 0.2 \text { a } 2 \text { puntos } \\
\text { por proyecto y año. } \\
\text { Diferenciando } \\
\text { según rol (IP, } \\
\text { colaborador, } \\
\text { contratado, etc.) y } \\
\text { dedicación pero no } \\
\text { ámbito. }\end{array}$ \\
\hline $\begin{array}{l}\text { Pablo de } \\
\text { Olavide }^{5}\end{array}$ & $\begin{array}{l}\text { No he podido } \\
\text { acceder a los } \\
\text { baremos } \\
\text { específicos. }\end{array}$ & $\begin{array}{lrr}\text { No he } & \text { podido } \\
\text { acceder a } & \text { los } \\
\text { baremos } & & \\
\text { específicos. } & \end{array}$ & $\begin{array}{l}\text { No he podido } \\
\text { acceder a los } \\
\text { baremos } \\
\text { específicos. }\end{array}$ & $\begin{array}{l}\text { No he podido } \\
\text { acceder a los } \\
\text { baremos } \\
\text { específicos. }\end{array}$ & $\begin{array}{llr}\text { No he } & \text { podido } \\
\text { acceder a } & \text { los } \\
\text { baremos } & & \\
\text { específicos. } & \end{array}$ & $\begin{array}{lrr}\text { No he } & \text { podido } \\
\text { acceder a } & \text { los } \\
\text { baremos } & & \\
\text { específicos. } & \end{array}$ \\
\hline Sevilla & \begin{tabular}{lr}
\multicolumn{2}{l}{ No especifica } \\
en & este \\
bloque & sino \\
en "IV". & \\
Hasta & 2 \\
puntos. &
\end{tabular} & $\begin{array}{l}\text { No especifica en } \\
\text { este bloque sino en } \\
\text { "III" } \\
\text { Hasta } 10 \text { puntos. }\end{array}$ & $\begin{array}{l}5 \text { puntos } \\
\text { No específica el } \\
\text { significado de } \\
\text { "tiempo } \\
\text { completo" ni el } \\
\text { número de } \\
\text { créditos. }\end{array}$ & $\begin{array}{l}\text { Hasta } 4 \text { puntos } \\
\text { Expone } \\
\text { únicamente } \\
\text { "Por artículos } \\
\text { publicados en } \\
\text { revistas } \\
\text { científicas". } \\
\text { No especifica } \\
\text { ningún } \\
\text { indicador para } \\
\text { evaluar la } \\
\text { calidad ni tipo } \\
\text { de indexación. }\end{array}$ & $\begin{array}{l}\text { Hasta un } 1 \text { punto } \\
\text { cada una. } \\
\text { No especifica tipo. }\end{array}$ & $\begin{array}{l}\text { Hasta } 2 \text { puntos } \\
\text { No especifica } \\
\text { ámbito, r rol, } \\
\text { dedicación } \\
\text { tiempo. }\end{array}$ \\
\hline
\end{tabular}

Fuente: Elaboración propia a partir de las convocatorias de los Boletines Oficiales autonómicos donde se han publicado las plazas de AD en las Universidades mencionadas. Los baremos de méritos de la Universidad de Granada y de la de Córdoba no vienen en los BOJAS sino en sus páginas webs: http://serviciopdi.ugr.es/contratado/concursopublico/ayudantedoctor/17-11-2015/convocatoria.htm y

\section{Notas Tabla 2}

1. Revistas indexadas en Web of Science (Thomson-ISI) 'Social Sciences Citation Index' (SSCI) y 'Journal Citation Reports.

2. Los criterios de valoración de méritos de la Universidad de Córdoba fueron aprobados en Acuerdo de Consejo de Gobierno (05/02/2015) para todas plazas PDI. Información disponible en el siguiente enlace https://sede.uco.es/bouco/bandejaAnuncios/BOUCO/2015/00032

3. Los criterios de valoración de méritos la Universidad de Granada son muy generales. Fueron aprobados en su Consejo de Gobierno de 23 de julio de 2004 y modificados en su sesión de 28 de julio de 2011 (BOJA 8 de agosto). La Comisión, una vez constituida y antes de acceder a los expedientes de los concursantes, hará públicos en el Tablón de Anuncios del Servicio de Personal Docente e Investigador los criterios de concreción a que se refiere el baremo general. El baremo final se publica únicamente en el tablón de anuncios de la facultad (formato papel) y en todos los casos después de que salgan las listas definitivas de admitidos por lo los/las solicitantes se presentan a las plazas sin saber los criterios que les van a aplicar a la hora de evaluarlos.

4. En la Universidad de Huelva cada comisión de baremación posteriormente publica tablas de afinidades y baremos para la plaza que evalúa (http://www.uhu.es/planificacion_personal_docente/normativa/contratados.htm). Como hemos dicho en la nota 4 de la tabla 1 las afinidades suelen ser muy generales. Esta Universidad especifica la baremación para la docencia de becarios/as de investigación (1 punto por año). Para la clasificación de las

Revista de Estudios Andaluces, vol. 34, núm. 1 (2017) pp. 529-543. e-ISSN: 2340-2776

http://dx.doi.org/10.12795/rea.2017.i34.18 
revistas en $A, B, C, D$, permite informe razonado por área. Aplica un coeficiente corrección a los artículos publicados por más de 4 autores/as.

5. Los criterios de valoración de méritos de la Universidad de Pablo de Olavide aparecen en los siguientes enlaces:

https://www.upo.es/upo_opencms/export/sites/upo/Galerias/Descargas/norm_UPO/normcontrprof.pd f y https://upo.gob.es/opencms/AlfrescoFileTransferServlet?action=download\&ref=69f7d735-bbd745b8-b898-0bcb34f703c7 Del mismo modo que los de la Universidad de Granada son muy generales y dan libertad a las Comisiones para adecuarlos según estimen oportuno. Este hecho puede apreciarse claramente en el siguiente párrafo: "Los Presidentes de las Comisiones de Contratación procederán para que las correspondientes Comisiones se constituyan para la elaboración del baremo específico mediante el cual se juzgará a los candidatos. Dicho baremo deberá remitirse al Área de Recursos Humanos al objeto de su publicación. El baremo general será de obligado cumplimiento. Sólo habiéndose recibido el baremo específico se remitirá la documentación para que sea evaluada por la Comisión de Contratación". Este procedimiento pone de manifiesto que puede darse el caso de que los baremos sean publicados una vez que se haya acabado el proceso de recepción de solicitudes de modo que los candidatos se presentarían sin saber cómo se les evaluarán los méritos. He intentado conseguir uno de los baremos específicos para las plazas de Ayudante Doctor del BOJA 15/07/2015 pero no ha sido posible puesto que pasado un tiempo los retiran del tablón electrónico oficial de la UPO donde los publican en formato digital (https://upo.gob.es/teo/index.jsp).

\section{FUENTES CONSULTADAS}

Bases Universidad de Granada. BOJA 8/8/2011

http://www.juntadeandalucia.es/boja/2011/154/24.

Bases generales de baremación Universidad Pablo de Olavide https://www.upo.es/upo_opencms/export/sites/upo/Galerias/Descargas/norm_UPO/ normcontrprof.pdf

Bases Universidad Pablo de Olavide.

https://www.upo.es/upo_opencms/export/sites/upo/Galerias/Descargas/norm_UPO/ normcontrprof.pdf

https://upo.gob.es/opencms/AlfrescoFileTransferServlet?action=download\&ref=69f7d 735-bbd7-45b8-b898-0bcb34f703c7

BOJA 25/11/2014 http://www.juntadeandalucia.es/boja/2014/230/BOJA14-23000015-19625-01_00058968.pdf Universidad de Sevilla.

BOJA 20/01/2015 http://www.juntadeandalucia.es/eboja/2015/12/BOJA15-01200013-480-01_00061831.pdf Universidad de Almería.

BOJA 18/03/2015 http://www.juntadeandalucia.es/boja/2015/53/14 Universidad de Córdoba.

BOJA 15/07/2015 http://www.juntadeandalucia.es/boja/2015/136/BOJA15-13600013-12291-01_00073339.pdf Universidad Pablo de Olavide.

Revista de Estudios Andaluces, vol. 34, núm. 1 (2017) pp. 529-543. e-ISSN: 2340-2776 http://dx.doi.org/10.12795/rea.2017.i34.18

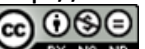

Esta obra se distribuye con la licencia Creative Commons Reconocimiento-NoComercialSinObraDerivada 4.0 Internacional 
BOJA 05/11/2015

http://www.uma.es/media/tinyimages/file/CONCURSO_AYD_16_10_15.pdf Universidad de Málaga.

BOJA 25/11/2015 http://www.juntadeandalucia.es/boja/2015/229/BOJA15-22900001-19635-01_00080548.pdf Universidad de Granada.

BOJA 03/12/2015 http://www.juntadeandalucia.es/boja/2015/235/BOJA15-23500007-20199-01_00081104.pdf Universidad de Huelva.

BOJA 15/12/2015 http://www.juntadeandalucia.es/eboja/2015/241/BOJA15-24100014-20798-01_00081684.pdf Bases Universidad de Jaén.

BOJA 11/01/2016 http://www.juntadeandalucia.es/eboja/2016/5/BOJA16-005-0001651-01_00082774.pdf Bases Universidad de Cádiz.

Revista de Estudios Andaluces, vol. 34, núm. 1 (2017) pp. 529-543. e-ISSN: 2340-2776 http://dx.doi.org/10.12795/rea.2017.i34.18

\section{(c) (i) $\Theta$} SinObraDerivada 4.0 Internacional 